\title{
Study on the efficiency of computed tomogram and ultrasonogram in the diagnosis of intra-abdominal injuries following trauma
}

\author{
Vadakkan Ouseph Thimothy*, Sreepadam Sundaran JinchuSundar
}

Department of General Surgery, Amala Institute of Medical Sciences, Amala Nagar, Thrissur, Kerala, India

Received: 19 August 2015

Accepted: 07 October 2015

*Correspondence:
Dr. Vadakkan Ouseph Thimothy,
E-mail: vothimothy@yahoo.com

Copyright: $(\odot$ the author(s), publisher and licensee Medip Academy. This is an open-access article distributed under the terms of the Creative Commons Attribution Non-Commercial License, which permits unrestricted non-commercial use, distribution, and reproduction in any medium, provided the original work is properly cited.

\begin{abstract}
Background: Blunt abdominal trauma (BAT) can be a big diagnostic dilemma even to the most experienced surgeon. Clinical signs along with imaging studies such as ultrasonogram (USG) and CT scan play a major role in decision making. A descriptive study was conducted to find out which imaging modality is most beneficial in evaluating BAT. Methods: Fifty patients with BAT (age ranges from 15 to 65 years) who had undergone imaging studies as well as laprotomy were included in the study. A thorough history was taken from the volunteers. Patients who presented with unstable vitals necessitating emergency surgery without imaging studies and those patients who were managed conservatively were excluded from the study.

Results: Results showed that $64 \%$ of BAT was due to road traffic accident (RTA). Age group 20-29 and male sex were the vulnerable groups for RTA. However, no statistically significant difference found between the age groups and etiology of BAT $(\mathrm{p}=0.204)$. Spleen was the most common organ injured, followed by liver and small bowel. Ultrasonogram (USG) could pick up 50\% of free fluid with a positive predictive value (PPV) of 96\%. But, it could pick up only $9.4 \%$ cases of multiple organ injury with PPV of $100 \%$. Sensitivity of computed tomogram (CT) scan in identifying splenic injury was $92.3 \%$ with PPV of $70.6 \%$. Sensitivity of CT scan in identifying multiple organ injury was $71.9 \%$ with PPV of $95.8 \%$.

Conclusions: Sensitivity of CT scan in identifying multiple organ injury is higher than that of USG. The result concluded that clinical suspicion along with appropriate imaging studies and watchful observation will help a surgeon in diagnosing even the most complicated BAT cases.
\end{abstract}

Keywords: Laprotomy, Trauma, Ultrasonogram, Blunt abdominal trauma, Computed tomogram, Splenectomy, Pancreatic transection

\section{INTRODUCTION}

Trauma is the most common cause of death in people younger than 45 years of age and accounts for more years of life loss than cancer, heart disease and stroke combined. ${ }^{1}$ 1Evaluation of patients who have sustained blunt abdominal trauma (BAT) may pose a significant diagnostic challenge to the most seasoned trauma surgeon. Motor vehicle accidents account for 75 to $80 \%$ of BAT. ${ }^{2}$ Fall from height, assault with blunt objects, sport injuries, industrial mishaps, bomb blast and fall from a bicycle are other causes for BAT. ${ }^{3}$ The spleen, liver and kidneys are the most commonly injured abdominal organs ${ }^{4,5}$ Missed splenic injury is the most common cause of preventable death. ${ }^{6}$

Since, nonoperative management was associated with a high mortality rate and significant risk of delayed rupture in the case of splenic injury, surgical management was the preferred treatment for most BAT. However, a significant amount of the laparotomies were nontherapeutic and therefore possibly unnecessary. ${ }^{7}$ Hence, clinical signs along with imaging techniques play a great role in decision making in cases of BAT. A descriptive 
study was conducted to find out which imaging modality is most beneficial in evaluating BAT and the findings are reported in this communication.

\section{METHODS}

\section{Subjects}

This descriptive study included 50 cases of abdominal injury presented to General Surgery department, Amala Institute of Medical Sciences, during the study period of 24 months. Patients with abdominal trauma of any severity who underwent USG abdomen and/or CT followed by surgery or patients who had to undergo surgery when conservative management failed (conservative management based on USG and CT findings) were included. In all the cases, the imaging findings were correlated with laparotomy findings. Haemodynamically unstable patients and patients who didn't undergo surgery after imaging were excluded from the study. A thorough assessment for injuries carried out. A detailed history had taken by direct interview with the patient or patients' relatives. Written consent was obtained from the patient or their relatives and the study design was approved by the Institutional ethics committee for research, Amala Institute of Medical Sciences. Haemodynamically unstable patients with obvious abdominal injuries were taken directly to the operation theatre. Haemodynamically stable patients with clinical suspicion of abdominal injury are subjected to imaging studies (USG abdomen and CT scan) and results are assessed. USG abdomen was done in all stable patients with suspected intra-abdominal injury. CT scan was done in cases where, (a) USG is inconclusive (b) USG is negative but there is strong clinical suspicion of injury and (c) For localizing site of bleed.

\section{Statistical analysis}

The statistical analysis was performed using SPSS (version 16.0). Chi-square was done to find the significant difference between the different age groups and cause of BAT. P less than 0.05 were considered as significant.

\section{RESULTS}

Total 50 cases (age 15 to 65 years; Mean age of presentation was 37.5 ) were selected for the study. Out of this, 44 males and only 6 were females. Percentage distribution of the sample according to sex is depicted in Figure 1. Table 1 has given with the percentage distribution of the sample according to age. In this study, most of the BAT was as a result of RTA (64\%), 24\% was caused by fall from height and $12 \%$ was as a result of assaults or direct hit by blunt objects in the abdomen (Figure 2).

Abdominal pain was the most consistent symptom which was present in $92 \%$ of cases. Vomiting was present only in about $26 \%$ of cases. Abdominal fullness was complained by more than $70 \%$ of cases. Vitals were mostly stable with the lowest systolic BP being 100. On examination, the distension was present in a considerable number of patients $(68 \%)$. Tenderness was a consistent finding which was present in about $94 \%$, while rebound tenderness was present only in $70 \%$ of cases. Guarding was the most consistent finding which was present in $98 \%$ of patients. Bowel sounds were absent in $70 \%$ of cases. Average $\mathrm{Hb}$ value, of all the cases, in the study was $10.5 \mathrm{~g} \%$. Minimum value was $7 \mathrm{~g} \%$ and maximum value was $15 \mathrm{~g} \%$. Maximum number of patients was having an $\mathrm{Hb}$ value in between 10 and 11 (Figure 3).

Table 1: Distribution of sample according to age.

\begin{tabular}{|lll|}
\hline Age & Count & Percent \\
\hline$<20$ & 7 & 14.0 \\
\hline $20-29$ & 12 & 24.0 \\
\hline $30-39$ & 7 & 14.0 \\
\hline $40-49$ & 10 & 20.0 \\
\hline$>=50$ & 14 & 28.0 \\
\hline
\end{tabular}

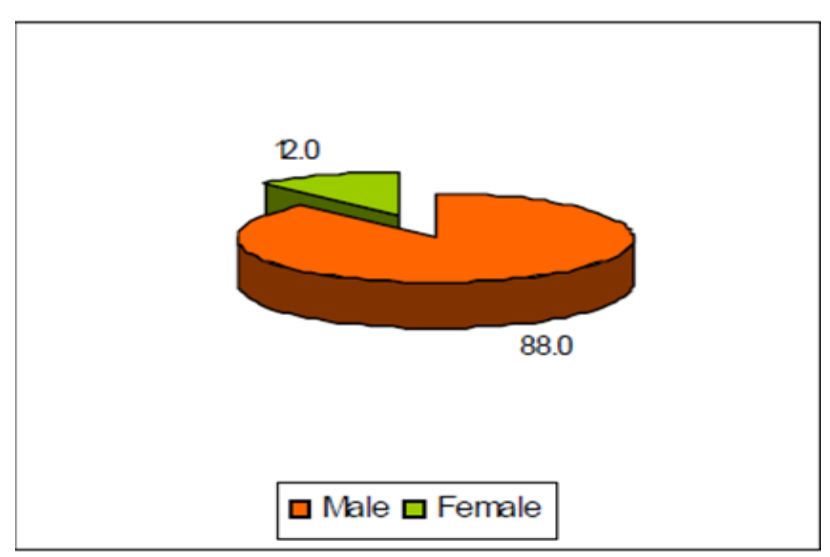

Figure 1: Gender wise distribution of bunt end abdominal trauma.

USG could pick up free fluid only in $50 \%$ of cases, splenic injury picked up in 23\%, liver injury in $14.7 \%$ and kidney injury in 3\%. Multiple organ injury was picked up in $8.8 \%$ (Figure 4 ). About $50 \%$ of patients had multiple organ injuries in CT. CT also picked up about $35.4 \%$ of isolated splenic injuries. Per operatively $64 \%$ had multiple organ injuries. About $9 \%$ of isolated splenic injuries and $2 \%$ of isolated liver injuries detected by CT were actually multiple organ injuries (Figure 5). $48 \%$ of patients were treated with splenectomy alone while $28 \%$ had to undergo multiple procedures inside abdomen. Even though isolated splenic injuries were only $26 \%$, most of the multiple organ injuries (32\%) necessitated splenectomy.

Postoperative period was uneventful in majority of cases $(82 \%)$. About $2 \%$ had minor complications like wound infection and dehiscence, while $4 \%$ had to undergo relaparotomy either due to recurrent hemorrhage or due 
to anastomotic dehiscence. Only one patient died postoperatively due to septicaemia.

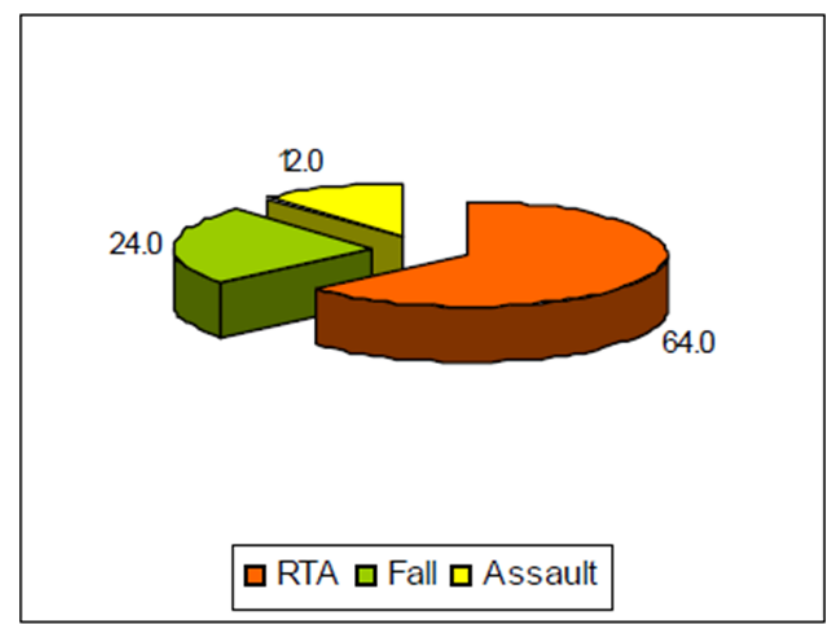

Figure 2: Distribution of blunt abdominal trauma based on mechanism. RTA: road traffic accidents.

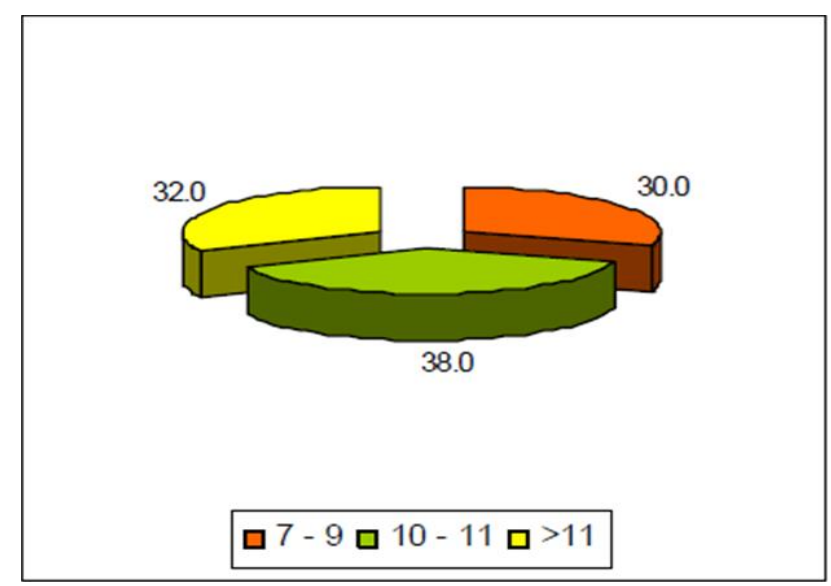

Figure 3: Distribution of haemoglobin among the patients.

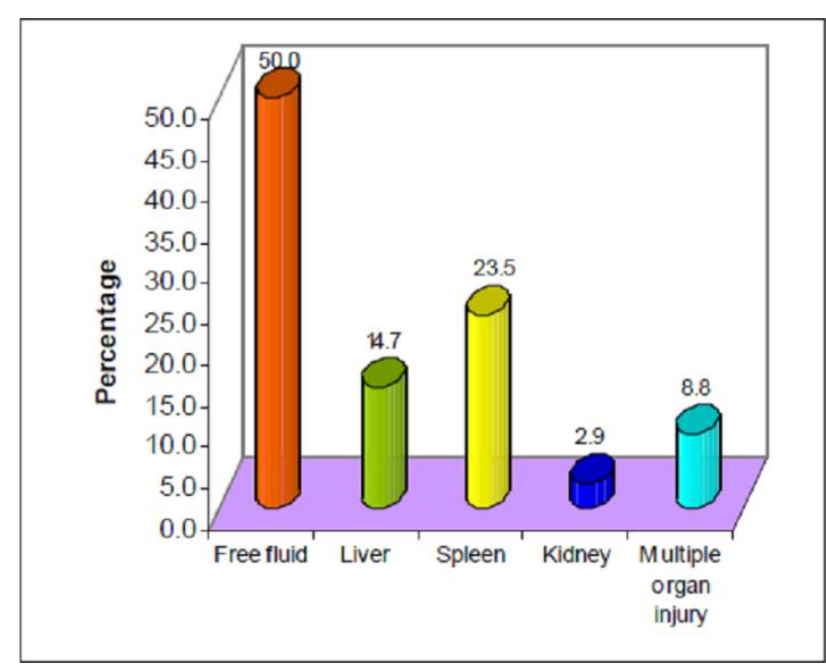

Figure 4: Distribution of blunt abdominal trauma based on ultrasonogram.

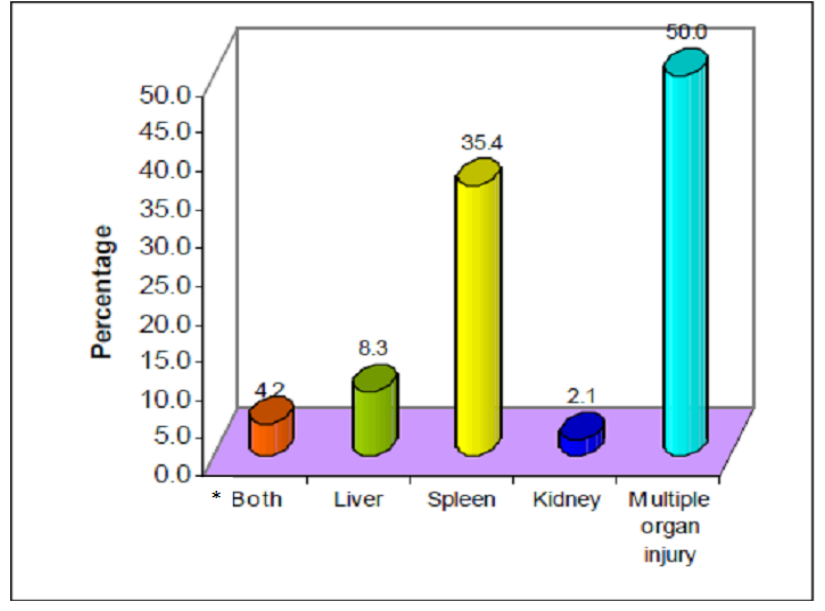

Figure 5: Distribution of blunt abdominal trauma based on computed tomogram. *Both: includes injury to liver and spleen.

\section{DISCUSSION}

Mechanism of injury was found to be RTA in $64 \%$ of cases. The result is comparable to the previous study by Mohapatra et al. in a single tertiary care centre in Northern India. ${ }^{8}$ Kulkarni et al. found out that $61 \%$ of cases resulted from RTA. ${ }^{9}$ Second major cause was found to be fall from height $(24 \%) .12 \%$ of injuries resulted from direct hit by blunt objects as in assault. Neeraj et al. recently reported that males have 4 fold increases in prevalence in RTA when compared to the females. Among them $50 \%$ of them were in age group of 16-30 years. ${ }^{10}$ The prevalence in males was again supported in the study by Nilamber et al. ${ }^{11}$

Most number of cases was from age group above 50 years. This was in contradiction to the studies by Ganveer et al., that most of the victims were in the age group 1837 years. ${ }^{12} 20 \%$ of cases were in the age group 20-29 and $14 \%$ were in age group 30-39. In another study by Davis et al. majority of patients belonged to 21-30 age group. ${ }^{3}$ Increased use of bikes among the youngsters can be considered as the major cause. Increased incidence of alcoholism and drunken driving in Kerala adds to the severity of the condition. Males were mostly affected $(88 \%)$.

Pain was the most consistent symptom (92\%), followed by abdominal swelling $(76 \%)$. Vomiting was an infrequent symptom in patients who underwent laparotomy. But, vomiting is one of the major symptoms in trauma patients coming to our hospital and is attributed mainly to head injury. Margay and Shahdhar in their study on BAT found that $77 \%$ of patients complained of abdominal pain and it is the most consistent symptom in BAT. ${ }^{13}$ Tripathy et al. also reported the abdominal pain in most of their cases $(91 \%) .{ }^{14}$

Vitals were mostly stable for all the patients included in the study. Mean pulse rate was $98 /$ min with a minimum 
of 68 and maximum of 120/min. Mean systolic BP was $110 \mathrm{~mm}$ of $\mathrm{Hg}$ with a minimum of 100 and maximum of $180 \mathrm{~mm}$ of $\mathrm{Hg}$. This is because all the patients included in the study were haemodynamically stable at the time of presentation. Abdominal tenderness was present in $94 \%$. But the most consistent sign was guarding (98\%). Abdominal distension was present in $68 \%$, rebound tenderness in $70 \%$ and absent bowel sounds in $35 \%$. Mohapatra et al and Tripathy et al found out in their study that tenderness was the most common symptom. ${ }^{8,14}$ The patients who present to the casualty with gross pallor are considered to be unstable and a focal abdominal ultrasound in trauma is done in all such cases. Abdomen was the site of pathology and patients were taken up for surgery. These patients were excluded from the study. This is the reason why most of the patients in this study are having $\mathrm{Hb}$ value above $10 \mathrm{gm} \%$. 38\% had an $\mathrm{Hb}$ value between 10 and 11. Average $\mathrm{Hb}$ value recorded was 10.5 ; minimum was 7 and maximum, $15 \%$.

Only $28 \%$ of patients had any associated chest injury. $8 \%$ had only rib fracture and no hemo or pneumothorax. $10 \%$ had only pneumothorax and $10 \%$ had hemopneumothorax. Sreenidhi et al. in a study conducted recently stated that they came across only $5 \%$ of chest injuries in BAT cases. But, they included patients who were treated conservatively also in their study. ${ }^{15}$ According to Magray and Shahdhar chest injuries were the most common associated injuries and constituted about $10 \%$ of cases. ${ }^{13}$ They also included all abdominal injury cases both operated and not operated in their study.

USG could pick up free fluid in 50\% of cases. Positive predictive value (PPV) of USG in picking up free fluid was 96 and identifying multiple organ injury was $100 \%$. But USG lacked sensitivity. Sensitivity of USG in predicting multiple organ injury was $9.4 \%$ and in predicting splenic injury was $23.1 \%$. Davis et al found that USG was able to predict splenic injury in 25,25 and $26 \%$ cases, respectively. ${ }^{3}$ Mesenteric injuries and bowel injuries were the most difficult injuries to predict on ultrasound. Ultrasound was helpful in detecting other solid organ injuries like liver and kidneys also.

CT scan was $92.3 \%$ sensitive in detecting splenic injury. According to Magray and Shahdhar, CT had sensitivity and PPV of $100 \%{ }^{13}$ But, our results were not convincing to that extent. There were a couple of situations where the CT report was complete disruption of spleen, but laparotomy showed only minor lacerations less than 3 $\mathrm{cm}$. The report of pancreatic transection, laparotomy showed only a small hematoma in the lesser sac. Sensitivity of CT in predicting multiple organ injury was 71.9\% and PPV was $95.8 \%$. Results were consistent with previous study results. PPV of CT in predicting splenic injury in this study was only 70.6 contrary to 98 by Magray and Shahdhar. ${ }^{13}$

\section{CONCLUSION}

RTAs are the major cause for blunt injury abdomen. A vast majority of blunt abdominal injuries can be treated conservatively. Age group 20-29 and male sex are the vulnerable groups. Many BATs present with unstable vitals, thus necessitating an immediate laparotomy. For those who are stable a contrast enhanced CT. is the gold standard investigation. CT is $92.3 \%$ sensitive in detecting a splenic injury. CT was also $71.9 \%$ sensitive in detecting multiple organ injury. PPV in either case were above $95 \%$. USG as an investigation is not sensitive to organ specific injuries. But, it can detect and quantify the amount of free fluid in cases where the patient is too unstable. Moreover, sensitivity of CT in diagnosing mesenteric tear and small bowel injury was much less than expected. Hence, clinical suspicion along with appropriate imaging studies and watchful observation will help a surgeon in diagnosing the most complicated BAT cases.

\section{ACKNOWLEDGEMENTS}

We acknowledge the valuable help of Dr. Ajith TA, Professor, Department of Biochemistry, during the preparation of this manuscript.

Funding: No funding sources

Conflict of interest: None declared

Ethical approval: The study was approved by the institutional ethics committee

\section{REFERENCES}

1. Krug EG, Sharma GK, Lozano R .The global burden of injuries. Am $\mathrm{J}$ Public Health. 2000;90:523-6.

2. Sabiston's Text book of surgery: 17 th edition. 2004;1:483-531.

3. Davis JJ, Cohn I, Nance FC. Diagnosis and management of blunt abdominal trauma. Ann Surg. 1976;183:672-8.

4. Esposito TJ, Gamelli RL. Injury to the spleen. Feliciano DV, Moore EE, Mattox KL. Trauma 3rd ed. Appleton \& Lange, Stamford. 1996:525-50.

5. Schroeppel TJ, Croce MA. Diagnosis and management of blunt abdominal solid organ injury. Curr Opin Crit Care. 2007;13:399-404.

6. Cales RH, Trunkey DD. Preventable trauma deaths. A review of trauma care systems development. JAMA. 1985;254:1059-63.

7. Sorkey AJ, Farnell MB, Williams HJ et al., The complementary roles of diagnostic peritoneal lavage and computed tomography in the evaluation of blunt abdominal trauma. Surgery. 1989;106:794-800.

8. Mohapatra S, Pattanayak SP, Rao KRRM, Bastia B. Options in management of solid visceral injuries from blunt abdominal trauma. Indian $\mathrm{J}$ Surg. 2003;65:263-8. 
9. Kulkarni MS, Hindlekar MM. Primary repair or colostomy in the management of civilian colonic trauma. Indian J Gastroenterol. 1995;14:54-6.

10. Neeraj K, Sanjay GK, Atul V, Athavale AV Epidemiological study of road traffic accident cases attending tertiary care hospital in Bhopal, Madhya Pradesh. National Journal of Community Medicine. 2012;3:395-9.

11. Nilamber J, Goutam R, Jagdish S. Epidemiological study of Road traffic cases: A study from South India. IJCM. 2004;21:20-4.

12. Ganveer GB, Tiwari RR. Injury pattern among nonfatal Road traffic accident cases: a cross sectional study in central. Indian J Med Sci. 2005;59:9-12.

13. Magray M, Shahdhar M, Wani M, Shafi M, Sheikh J, Wani H. Studying The Role Of Computed
Tomography In Selective Management Of Blunt Abdominal Trauma Patients In A Single Tertiary Care Centre In Northern India. The Internet Journal of Surgery. 2013;30:1-5.

14. Tripathi MD, Srivastava RD, Nagar AM, Pratap VK, Dwivedi SC. Blunt abdominal trama with special reference to early detection of visceral injuries. Indian I Surg. 1991;53:179-84.

15. Sreenidhi G. M, Venugopal K, Nandeeshkumar G. N. A clinical study and management of abdominal injuries. 2014;3:10756-71.

Cite this article as: Thimothy VO, JinchuSundar SS. Study on the efficiency of computed tomogram and ultrasonogram in the diagnosis of intra-abdominal injuries following trauma. Int Surg J 2015;2:604-8. 